Article

\title{
Sustainable Design and Prototyping Using Digital Fabrication Tools for Education
}

\author{
Sohail Ahmed Soomro ${ }^{1,2}\left(\mathbb{D}\right.$, Hernan Casakin ${ }^{3}\left(\mathbb{D}\right.$ and Georgi V. Georgiev ${ }^{1, *(D)}$ \\ 1 Center for Ubiquitous Computing, University of Oulu, 90570 Oulu, Finland; sohail.soomro@oulu.fi \\ 2 Department of Electrical Engineering, Sukkur IBA University, Sukkur 65200, Pakistan \\ 3 School of Architecture, Ariel University, Ariel 44837, Israel; casakin@ariel.ac.il \\ * Correspondence: georgi.georgiev@oulu.fi
}

check for updates

Citation: Soomro, S.A.; Casakin, H.; Georgiev, G.V. Sustainable Design and Prototyping Using Digital

Fabrication Tools for Education.

Sustainability 2021, 13, 1196. https:// doi.org/10.3390/su13031196

Received: 29 December 2020

Accepted: 19 January 2021

Published: 23 January 2021

Publisher's Note: MDPI stays neutral with regard to jurisdictional claims in published maps and institutional affiliations.

Copyright: (c) 2021 by the authors. Licensee MDPI, Basel, Switzerland. This article is an open access article distributed under the terms and conditions of the Creative Commons Attribution (CC BY) license (https:/ / creativecommons.org/licenses/by/ $4.0 /)$.

\begin{abstract}
Prototyping physical artifacts is a fundamental activity for both product development in industrial and engineering design domains and the development of digital fabrication skills. Prototyping is also essential for human-centric problem-solving in design education. Digital fabrication assists in rapid prototype development through computer-aided design and manufacturing tools. Due to the spread of makerspaces like fabrication laboratories (FabLabs) around the world, the use of digital fabrication tools for prototyping in educational institutes is becoming increasingly common. Studies on the social, environmental, and economic sustainability of digital fabrication have been carried out. However, none of them focus on sustainability and prototyping-based digital fabrication tools or design education. To bridge this research gap, a conceptual framework for sustainable prototyping based on a five-stage design thinking model is proposed. The framework, which is based on a comprehensive literature review of social, economic, and environmental sustainability factors of digital fabrication, is applied to evaluate a prototyping process that took place in a FabLab in an education context aimed at enhancing sustainability. Three case studies are used to evaluate the proposed framework. Based on the findings, recommendations are presented for sustainable prototyping using digital fabrication tools.
\end{abstract}

Keywords: sustainability indicators; prototyping; digital fabrication; design education; FabLab; makerspace

\section{Introduction}

Various definitions of a prototype can be found in the literature [1-3]. In this study, a prototype is defined as "a concrete representation of part or all of an interactive system" and as "a tangible artefact, not an abstract description that requires interpretation" [4]. As the word prototype suggests, it is the outcome of the prototyping activity. Indeed, the prototyping activity and its outcome help to improve design $[1,5,6]$. Prototyping provides an opportunity to transform a design idea into a tangible form. This activity is frequently carried out by product development designers from the earlier stages of the design process. Architects, engineers, and designers use prototypes for concept testing and evaluation purposes. Prototyping is highly relevant in design education, where students learn how to produce creative idea solutions for real-life problems [7]. Different types of prototype processes exist [6,8]. Digital fabrication is one of them [9] and is largely affected by the manner that designers think.

Design thinking is concerned with the generation of ideas while tackling a design problem and transforming them into a solution. Among many models that can be found in the literature, Stanford's design thinking model relates to a well-established conceptual framework in which the development of a solution leads to a concrete product [10]. This model is used for the sake of creating human-centric product solutions. It is composed of five steps, the fourth of which is to prototype. This is the step where prototyping, digital fabrication, and design thinking come into place [9]. In the present technological era, 
digital fabrication is characterized by the use of convenient techniques that facilitate the rapid creation of tangible prototypes using CAD and CAM tools. The digital fabrication techniques are used in a variety of disciplines ranging from architectural to industrial design [7,11-13]. Several studies have examined the role of digital fabrication tools in the design education context. Kim [14] highlights the importance of digital fabrication tools such as parametric design software, 3D printers (additive manufacturing), and Computer numerical control (CNC) milling (subtractive manufacturing process) in architectural design education. Researchers explore the contribution of these techniques in STEM and STEAM education [15-18]. Digital fabrication techniques have gained popularity in educational environments all over the world, mainly due to the influential role of the Fabrication Laboratory (FabLab) from MIT [19], the makerspaces [20], and the rapid prototyping laboratories [21].

The increasing use of these digital fabrication tools raises questions regarding the extent to which the fabrication process can be sustainable and has become the core of the debate in the literature. For example, Corsini and Moultrie [22] conducted a comprehensive study on the social aspects of digital fabrication for humanitarian development. They suggested a framework aimed at dealing with the social sustainability of design implemented through digital fabrication [22]. In another study, the life cycle assessment (LCA) of a digital fabrication-based prototype was discussed by Lazaro Vasquez et al. [23]. In their work, the use of conventional materials for prototype development is replaced by biomaterial to improve the environmental sustainability and life cycle of prototypes. Kohtala et al. [24] propose the use of new technologies and environmentally friendly materials to improve sustainability in digital fabrication. Agusti-Juan et al. [25], who studied the role of 3D printing to improve sustainability in construction, offer environmental guidelines to make digital fabrication tools more sustainable.

The above studies explore social, environmental, or economic aspects of sustainability but do not investigate all these aspects together. Digital fabrication tools used for prototyping are not only relevant at the higher education level, but also for STEM and primary education [20]. Despite its importance, no study has addressed sustainability and prototyping-based digital fabrication tools in the design education context. A conceptual framework focusing on all major aspects of sustainability in digital fabrication-based prototyping in the educational environment has yet to be proposed to fill this research gap. Therefore, the objectives of the present study are: firstly, based on existing literature, to propose a conceptual framework that combines design thinking, digital fabricationbased prototyping, and sustainability and secondly, to test this comprehensive conceptual framework empirically in the context of design education. It is expected that the present study will allow a deeper understanding of the contribution of sustainability to digital fabrication during design problem-solving, with important implications for education environments such as design courses dictated in FabLabs. The outcomes of this study will encourage designers, instructors, and students to become more aware of the importance of sustainability in the digital fabrication process. For the scope of this study see Figure 1.

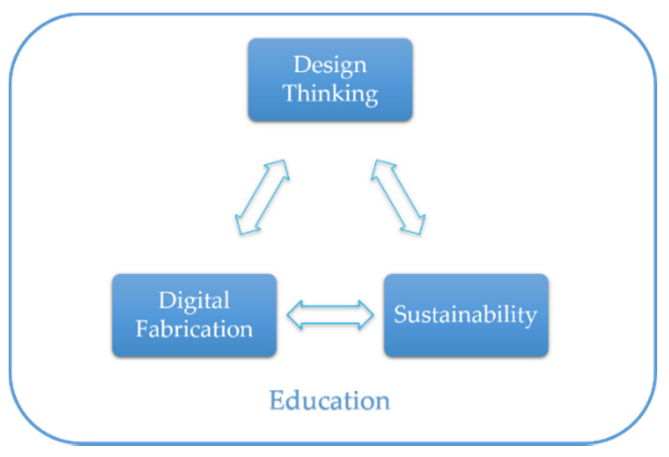

Figure 1. Scope of this study. 


\section{Literature Review}

To explore the existing work on sustainability issues in digital fabrication-based projects, a comprehensive literature review is conducted. After inspecting the scope of this topic, four major keywords were identified: prototype or prototyping, sustainable or sustainability, digital fabrication, and design education. Carrying out an initial search using prototype or prototyping keywords led to too many results, and using all four keywords at once ended up with only a few outcomes. Hence, it was decided to stick with sustainable or sustainability and digital fabrication keywords to gain a comprehensive view of the literature on sustainability issues in digital fabrication. A logical approach was adopted to find relevant peer-reviewed articles available on the Scopus and Web of Science databases using the AND operator between sustainable or sustainability and digital fabrication keywords. The decision to use Scopus and Web of Science databases as search tools was made sense because they cover many academic disciplines of science, arts, and engineering. The current search was limited to peer-reviewed journal articles published in English. A total of 64 journal articles were initially found in these databases. Forty-five articles remained after removing duplicates. The next phase consisted of screening for relevant articles. Twentysix out of 45 articles were found to be related to the application of digital fabrication in architecture and construction. After removing duplicates and irrelevant articles, only 16 articles were found to be relevant to the scope of this research. After a discussion among all the authors, two conferences $[23,26]$ and one further journal article [27] were identified through snowballing and included in the literature review due to their relevance and contribution to this study. In total, 19 articles were found to be eligible for inclusion in the literature review. The complete searching process is described in Figure 2. The filters and instructions used during the search are provided in Table 1.

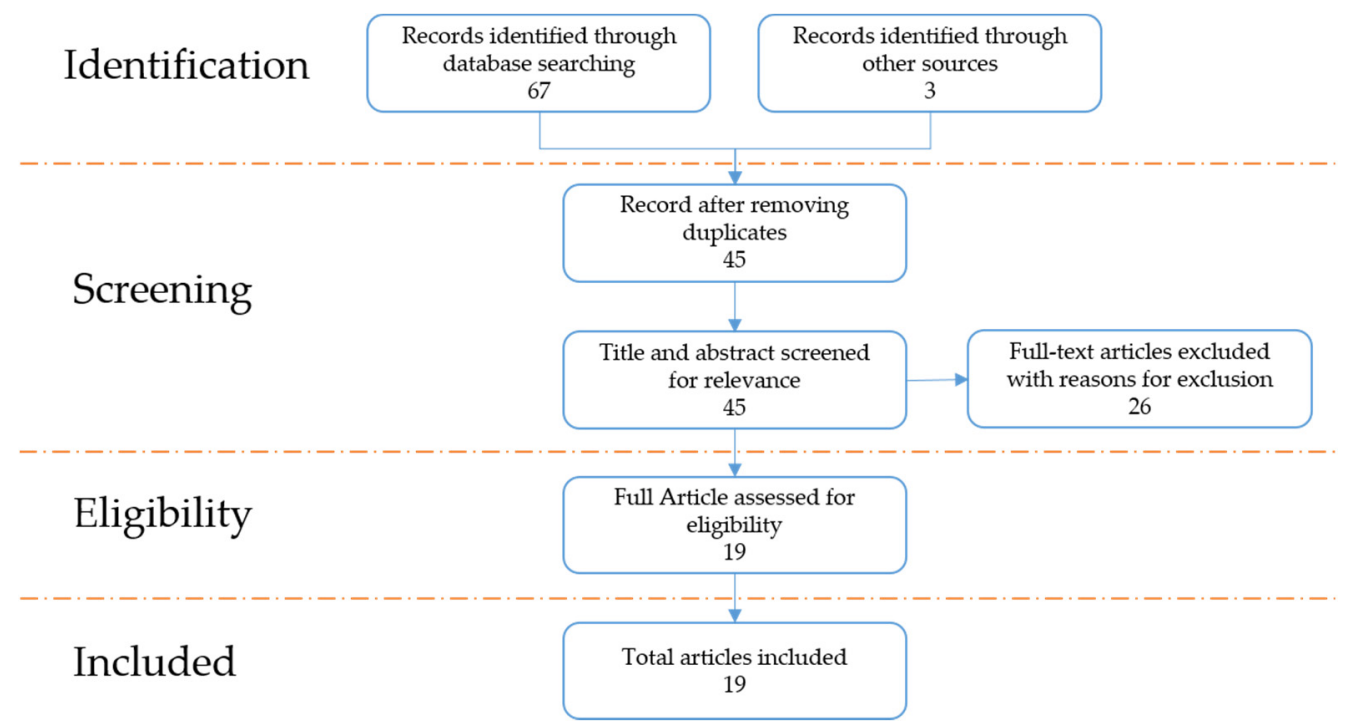

Figure 2. Literature review process.

Table 1. Criteria used while carrying out the literature search.

\begin{tabular}{cc}
\hline Search & (Sustainable OR Sustainability) AND “Digital Fabrication” \\
\hline Database & Scopus and Web of Science \\
\hline Document Type & Journal Articles \\
\hline Language & English \\
\hline Relevance & $\begin{array}{c}\text { Articles selected only focused on sustainability issues in digital } \\
\text { fabrication while designing or making a product or its prototype }\end{array}$ \\
\hline Date & 19 November 2020 \\
\hline
\end{tabular}


Table 2 summarizes all 19 articles we found in the literature review described above. It also indicates the focus of the research papers included in the review in terms of the sustainability aspect they address and its context (i.e., digital fabrication, prototyping, or design education). It is worth mentioning that there is a limited number of articles centering on the sustainability of prototyping using digital fabrication in the educational context. Hence, this is the gap addressed in this article. However, the sustainability of digital fabrication tools is a topic that is widely discussed [24,28-30]. Digital fabrication is the technology used for prototyping and product design and development [11,31]. This is why research on the sustainability of digital fabrication can be related to prototyping activity. The prototyping activity is largely based on digital fabrication tools due to their availability in most makerspaces and FabLabs in many universities around the globe [32].

Table 2. Literature review summary.

\begin{tabular}{|c|c|c|c|c|c|c|c|c|}
\hline ટ્ટ & Title & 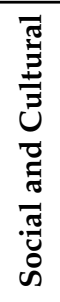 & 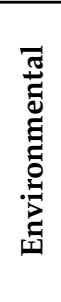 & 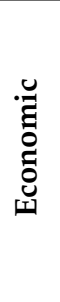 & 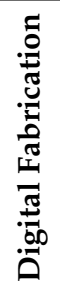 & 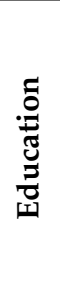 & $\begin{array}{l}\infty \\
.5 \\
0 \\
0 \\
0 \\
0 \\
0 \\
0 \\
0 \\
0\end{array}$ & 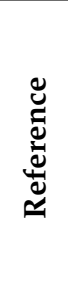 \\
\hline 2020 & $\begin{array}{c}\text { A New Player for Tackling Inequalities? Framing the Social Value and } \\
\text { Impact of the Maker Movement }\end{array}$ & $\checkmark$ & & & $\checkmark$ & & & [33] \\
\hline 2019 & $\begin{array}{l}\text { "From Souvenirs to 3D Printed Souvenirs". Exploring the Capabilities of } \\
\text { Additive Manufacturing Technologies in (Re)-Framing Tourist Souvenirs }\end{array}$ & $\checkmark$ & & & $\checkmark$ & & & [34] \\
\hline 2019 & $\begin{array}{l}\text { Design for Social Sustainability: Using Digital Fabrication in the } \\
\text { Humanitarian and Development Sector }\end{array}$ & $\checkmark$ & & & $\checkmark$ & & & [22] \\
\hline 2019 & $\begin{array}{l}\text { Strategic Knowledge Management a Digital Environment: Tacit and } \\
\text { Explicit Knowledge in Fab Labs }\end{array}$ & $\checkmark$ & $\checkmark$ & $\checkmark$ & $\checkmark$ & & & [35] \\
\hline 2019 & $\begin{array}{l}\text { The Environmental Value and Impact of the Maker Movement-Insights } \\
\text { from a Cross-Case Analysis of European Maker Initiatives }\end{array}$ & & $\checkmark$ & $\checkmark$ & $\checkmark$ & & & [36] \\
\hline 2018 & Is the Maker Movement Contributing to Sustainability? & $\checkmark$ & $\checkmark$ & $\checkmark$ & $\checkmark$ & & & [28] \\
\hline 2018 & Participatory Design for Sustainable Social Change & $\checkmark$ & & & $\checkmark$ & $\checkmark$ & & [29] \\
\hline 2017 & $\begin{array}{l}\text { Making "Making" Critical: How Sustainability Is Constituted in Fab } \\
\text { Lab Ideology }\end{array}$ & $\checkmark$ & $\checkmark$ & & $\checkmark$ & & & [30] \\
\hline 2016 & $\begin{array}{l}\text { How to Deliver Open Sustainable Innovation: An Integrated Approach for } \\
\text { a Sustainable Marketable Product }\end{array}$ & & $\checkmark$ & $\checkmark$ & $\checkmark$ & & & [37] \\
\hline 2016 & $\begin{array}{c}\text { Making Things in Fab Labs: A Case Study on Sustainability } \\
\text { and Co-Creation }\end{array}$ & $\checkmark$ & $\checkmark$ & & $\checkmark$ & & $\checkmark$ & [38] \\
\hline 2016 & Attachment, Durability and the Environmental Impact of Digital DIY & & $\checkmark$ & & $\checkmark$ & $\checkmark$ & & [39] \\
\hline 2016 & Social Sciences in the Transdisciplinary Making of Sustainable Artifacts & $\checkmark$ & & & $\checkmark$ & & $\checkmark$ & [40] \\
\hline 2016 & $\begin{array}{c}\text { Sustainable Technologies and Transdisciplinary Futures: From } \\
\text { Collaborative Design to Digital Fabrication }\end{array}$ & $\checkmark$ & $\checkmark$ & & $\checkmark$ & $\checkmark$ & & [31] \\
\hline 2015 & $\begin{array}{l}\text { Designing Digital Fabrication Learning Environments for Bildung: } \\
\text { IMPLICATIONS from Ten Years of Physical Computing Workshops }\end{array}$ & $\checkmark$ & & & $\checkmark$ & & & [41] \\
\hline 2015 & Anticipated Environmental Sustainability of Personal Fabrication & & $\checkmark$ & & $\checkmark$ & & & [24] \\
\hline 2011 & Practices in the Creative Reuse of E-Waste & & $\checkmark$ & $\checkmark$ & & & & [26] \\
\hline 2020 & $\begin{array}{c}\text { Introducing the Sustainable Prototyping Life Cycle for Digital Fabrication } \\
\text { to Designers }\end{array}$ & & $\checkmark$ & & $\checkmark$ & & $\checkmark$ & [23] \\
\hline 2016 & Makespaces: From Redistributed Manufacturing to a Circular Economy & & $\checkmark$ & $\checkmark$ & $\checkmark$ & & & [27] \\
\hline
\end{tabular}




\subsection{Social Sustainability}

Social sustainability is a central topic discussed in many articles in the literature (see Table 2). This notion is defined in many ways in the literature [42-44]. In this study, the clear and simple definition by Corsini and Moultrie was adopted: "Social sustainability is necessary to sustain positive change that addresses pressing social challenges" [22]. These authors proposed a framework for social sustainability evaluation of designs made through digital fabrication for the humanitarian development sector. The first two stages (product and process) of that framework are applicable for digital fabrication-based prototypes, provided that the technology (digital fabrication) considered in their study is similar to that employed in the present research.

\subsection{Environmental and Economic Sustainability}

Environmental sustainability is another central concept discussed in the literature $[13,14,25]$. To understand this notion in digital fabrication-based projects, two factors should be referred to: the material and the process used in making the prototypes $[23,45]$. Literature addressing the environmental sustainability of digital fabrication recommends the use of renewable material and the efficient employment of tools $[11,38]$. Forthcoming design projects can be evaluated by the life cycle assessment (LCA) approach [23]. In the digital fabrication context, LCA centers on issues such as waste reduction, energy consumption, recycling, and reuse.

Prendeville et al. [27] noted that embedding the concept of circular economy and redistributed manufacturing in makerspaces (place with digital fabrication tools) can create a suitable environment for sustainable product development. It hinges on product reuse, repair, remanufacture, and recycling. This notion is in contrast to conventional linear economy, which is to take-make-waste products. The concept of redistributed manufacturing is to make the product locally instead of at a centralized production facility. It can reduce supply chains and transportation. Redistributed manufacturing therefore reduces environmental impact due to energy consumption and transportation. It can be concluded that reuse, repair, remanufacture, and local manufacturing are the factors for the environmental and economic sustainability of digital fabrication-based production. Hence, the environmental and economic sustainability of digital fabrication-based projects can be divided into material and process groups, which are discussed below.

\subsubsection{Environmental and Economic Impacts of Materials Used in Digital Fabrication}

Vasquez et al. [23] proposed a life cycle assessment method based on material and manufacturing processes for digital fabrication projects and concluded that the use of biomaterials in prototyping contributes to making the process more sustainable. These researchers also indicated that waste reduction can improve sustainability in prototyping activity in FabLabs. They found that laser-cutting- and 3D printing-based prototypes generate $37 \%$ and $22 \%$ of waste, respectively. They also indicated the end-of-life and recycling factor of sustainability in their findings. Moreover, they showed that $47.5 \%$ of unused prototypes are placed in FabLabs for more than one year after their usage, and 27.5\% are kept for 6 months to a year in FabLabs and become part of the waste. Nevertheless, many components of these prototypes, such as electronic components and material, can be reused or recycled. Since electronic components are among the most common parts used in digital fabrication-based prototypes, the reuse of these components can help in the reduction of e-waste [26,46]. Similar studies about environmental and economical sustainability indicators are listed in Table 2. Transportation was also identified as an important indicator affecting design sustainability. Birtchnell et al. [47] noted that the environmental impact due to long-distance transportation can be reduced by making products locally. This is aligned with the concept of redistributed manufacturing described by Prendeville et al. [27]. 


\subsubsection{Environmental and Economic Impacts of Machines Used in Digital Fabrication}

The machinery employed in digital fabrication has an important effect on environmental and economic aspects. Faludi et al. studied the environmental impacts of 3D printers and CNC machines, considering popular digital fabrication tools [48]. While analyzing the environmental impact, these researchers focused on energy consumption, material waste, and high and low utilization of these types of equipment. They reported that energy consumption of 3D printers is frequent, but in the case of higher utilization of CNC machines, material waste becomes much higher. However, they found that energy utilization in idle time was an important parameter that reduces energy efficiency. They concluded that higher and well-planned utilization of 3D printers and CNC machines can balance energy consumption or machine usage for the produced parts. Similar parameters were considered to evaluate the environmental impact of these machines [49,50]. A laser cutter machine was found to emit gases that are not considered environmentally friendly [51]. When employed for cutting metal and engraving any other material, they consume even more energy than $\mathrm{CNC}$ machines [52]. However, the gas emission produced could be reduced by selecting the appropriate material and type of laser cutter, i.e., fiber or $\mathrm{CO}_{2}$ types. In addition to the environmental impact, the cost of usage of metal cutting machines is also studied in literature [53].

\subsection{Sustainability Indicators}

In the first stage, the authors identified from the literature 20 sustainability indicators in the context of digital fabrication. In a second stage, they classified these indicators into three main categories based on their usability and applicability. The indicators and their corresponding categories are summarized in Table 3, with corresponding references.

The recycling indicator reflects the use of recyclable material $[23,39]$. The reusability indicator represents the reuse of electronic components and material from previously built projects/prototypes [26,46]. The transportation indicator refers to local production and the use of locally available materials to reduce environmental and economic transportation impact $[25,27]$. The energy consumption indicator denotes the energy utilized by machines in the manufacturing process $[25,45,48]$. The waste reduction indicator represents the excessive use of material during the fabrication process [23,45,46,54]. Material waste is usually caused when the prototyping process lacks optimization and therefore leads to more than a single iteration. The emission indicator represents the emission of unsafe gases like $\mathrm{HCN}$, $\mathrm{NO}_{2}, \mathrm{CO}, \mathrm{CO}_{2}, \mathrm{HOCH}, \mathrm{CoCl}_{2}$, and styrene from laser cutting machines [23,51,55]. The amount and type of emission depend on the material used and the type of laser cutter (Fiber $/ \mathrm{CO}_{2}$ ) [51]. The end-of-life indicator refers to the possibility of reusing parts and material of the prototype after testing it $[23,56]$. This factor can be attained by utilizing most of the material of the current prototype for future prototypes. Finally, the social sustainability indicators were based on the work of Corsini and Moultrie [22], who grouped them into product and process categories. The product category included: need, suitable, access, usability, quality, adjustability, inclusive and complementary. The process category included: local manufacture, local control and repair, collaborative, transparent, and scalable. These social sustainability indicators refer to the degree of social sustainability product design possesses.

\section{Materials and Methods}

From the literature review outlined above, it can be concluded that there is an emerging body of work on sustainability regarding digital fabrication, but not in connection to prototyping in general, or prototyping in design education in particular. Dealing with this research gap can be helpful to enhance sustainability awareness in prototyping activities carried out in FabLabs [57] and makerspaces [58]. To this aim, a conceptual framework for sustainable prototyping based on a five-stage design thinking model is proposed. The framework, which is based on a comprehensive literature review of social, economic, and environmental sustainability factors of digital fabrication, is described as follows. 


\subsection{Stanford Design Thinking Process}

The Stanford design thinking process [10] is a human-centric model used to solve commercial real-life problems. The model was found to be effective in design education, since it offers a systematic approach to tackling problems and coming up with creative solutions [59]. Because of its effectiveness, it is used in education and in this study. It consists of the following five stages: empathize, define, ideate, prototype, and test. Instead of using a linear approach, it uses a continuous process to improve the solution. In the empathy stage, the user needs and opinions are analyzed by a personal interview. The designer tries to understand all the aspects of the product related to the user before designing the product in the empathy stage. In the definition stage, a one line definition of the core problem is written to clearly express and explain the problem. This definition also includes the requirement of the product under question. In the ideate stage, designers have to come up with all possible ideas to create the product. In the prototype stage, a working model is created that can solve the user problem, and this prototype also helps to improve the design with users' input. In the test stage, the prototype is provided for the user to use, and the designer seeks information on how the product is used and notices the features that can be improved.

Our study mainly focuses on the last three stages of the design thinking model, as they are directly related to the prototyping process. Hence, only the stages of the model rather than the interaction loops were included in the Stanford design thinking process [10].

\subsection{Digital Fabrication}

Rapid prototype development using digital fabrication tools is considered the most convenient approach for prototyping. These tools provide the facility to create computer designs of the prototype first, and then use them to make the prototype. This approach is called computer aided design (CAD) and computer aided manufacturing (CAM). Digital fabrication tools are also increasingly popular because of makerspaces around the globe. One example is the digital fabrication laboratory (FabLab) idea presented by Neil Gershenfeld [19]. FabLabs have become very popular educational environments, as there are more than 1000 FabLabs with digital fabrication facilities in universities, colleges, and schools [60]. FabLab provides facilities for all digital fabrication tools, such as 3D designing and printing, electronic circuit design and PCB milling, large CNC machines, 3D scanning, laser cutting, molding, and casting. These laboratories are highly suitable for prototyping activities using digital fabrication tools. Fleischmann et al. [38] commented, "Fab Labs can potentially be the places that encourage sustainable design, where people can produce products locally and think about the various implications for the environment and society of their design". Hence, making digital fabrication-based prototyping sustainable will have a significant impact on the associated environmental, social, and economic factors.

\subsection{Proposed Framework for Sustainable Design and Prototyping}

The sustainability indicators of digital fabrication identified in the literature (see Table 3) are related to the five-stage Stanford design thinking model as part of the proposed conceptual framework (see Figure 3). The first and second stages of the model consist of understanding and defining the design problem, and therefore they do not relate to any sustainability measure. The third stage is about ideation, where ideas are generated for further product development. Once an idea is selected, it is evaluated for social sustainability using the Design for Social sustainability (DfSS) framework [22], as shown in Figure 3. The fourth stage of the design thinking process is to prototype. In this stage, digital fabrication is employed as the main tool for developing the prototype. This activity can be divided into three parts: designing using CAD software, material, and process. In the first part, the design of the prototype is produced. The design optimization using CAD software helps to reduce energy consumption, waste induced, and gas emissions. The three indicators of energy consumption, waste induced, and gas emission focus on the main sustainability indicators concerned with the prototyping process. The three 
other sustainability indicators dealing with recycling, reusability, and use of local material (transportation) are related to the materials used during the prototyping activity. The final stage of the design model consists of testing the prototype. In consequence, the prototype can be disassembled, and the reusable parts can be detached. This is called an end-of-life indicator, as shown in Figure 3.

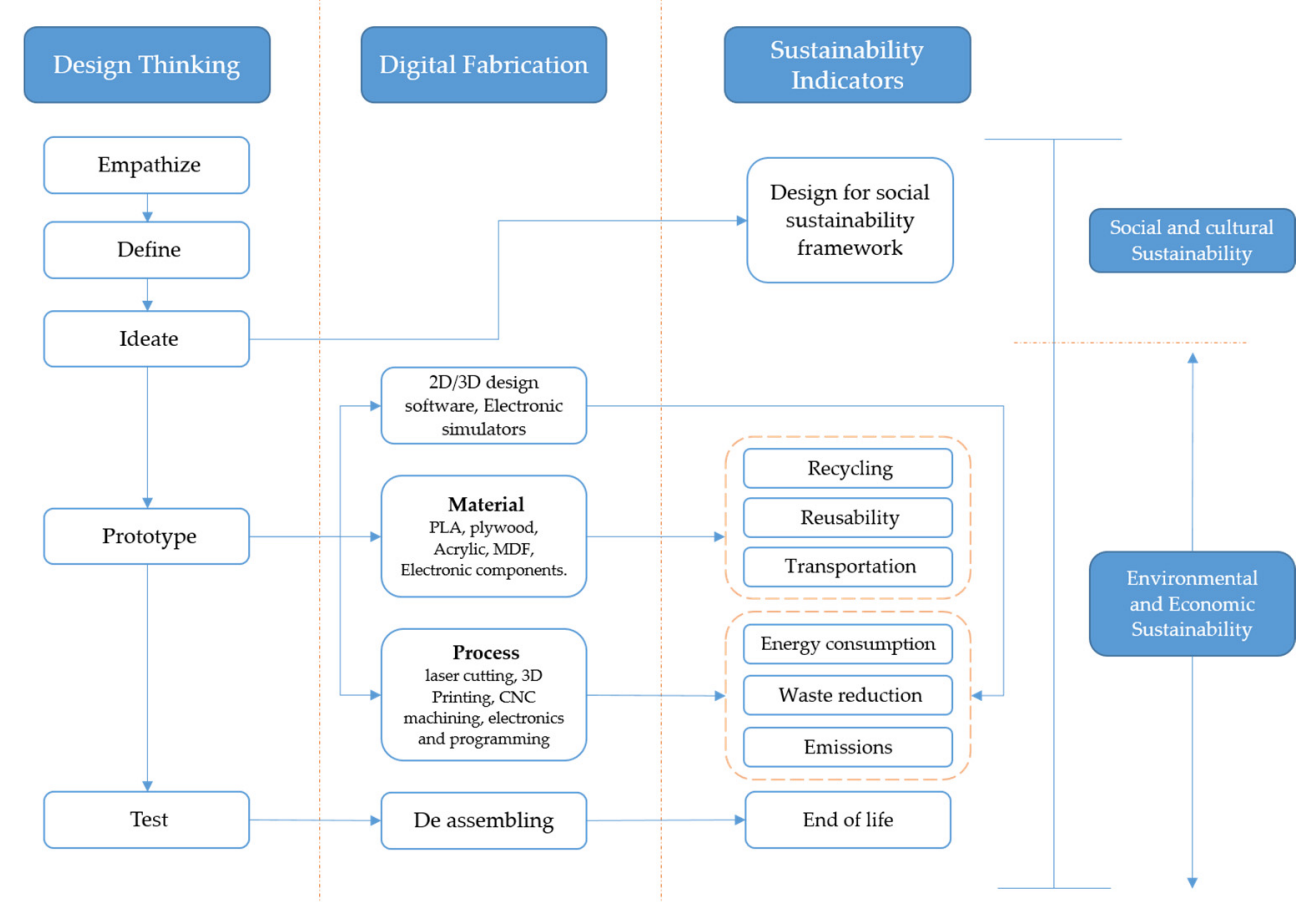

Figure 3. Proposed framework for digital fabrication based sustainable design and prototyping.

\subsection{Principles of Digital Fabrication Course}

The proposed framework for digital fabrication-based sustainable design and prototyping was implemented in the Principles of Digital Fabrication course. The course, which included 87 students, was aimed at helping develop design knowledge and skills during a digital fabrication process in a FabLab environment. Moreover, a major aim was to promote several aspects of sustainability. At the beginning of the academic period, course leaders gave a series of six lectures to students on sustainable design and prototyping practices. These included presentations focusing on the main themes included in the proposed framework, including awareness of design and sustainability. Above all, the lectures were aimed at enhancing the theoretical background of sustainability and of digital fabrication tools and their application in transforming ideas into a physical prototype. In the second part of the course, students implemented the content delivered in the lectures in a practical design prototyping task. During this period, relying on the expert opinion of instructors and other specialized personnel, optimal solutions were encouraged by providing feedback on the design ideas for the prototypes, alternative solutions, materials, and the reuse of existing product components. Explicit and detailed instructions were given to the students to optimize the digital fabrication process and materials. As part of the course philosophy, a portion of the electronic components in the produced prototypes were reused in later courses.

The design task of the course was to design an interactive 3D prototype, create basic electronics, implement control logic for an open hardware embedded board, design mechanical parts for prototype, and work in teams on a project. Some of goals of the course consisted of designing mechanical components by using solid modeling tools, building necessary electronics, implementing software with a microcontroller, and creating a prototype of a physical interactive gadget. The course was offered as part of a BSc 
in computer science, but students from other programs in the university participated. Students worked in teams of three to four members. They were free to decide the type of project they wanted to work on. However, digital fabrication tools were requested for the development of the design prototype. At the beginning, they were guided by their instructors on how to generate design ideas while working with teammates. Teams were encouraged to post the ongoing development of their project on a web-based blog (website provided by the course instructors). The weekly posts were available to both students and instructors to visit and comment on. Another course requirement was to document the prototyping process so that they could post all the problems they had faced and the approaches they used to solve them. Students were asked to finalize the project by the end of the seventh week, after which the instructors reviewed the design process and the produced outcomes. Scores were assigned to students based on the quality of the design prototypes, on sustainability and digital fabrication indicators, and on the design process and outcomes outlined in the proposed framework.

\subsection{Selection of Case Studies}

Three case studies were used as examples of the outcomes produced by the students in the Principle of Digital Fabrication course to evaluate the relevance of the proposed framework. These projects were selected based on the following criteria: first, a minimum of three to four students working in a team to develop the prototype (co-creation); second, the project was carried out in a FabLab educational setting, where students learn to generate ideas and develop prototype solutions using a human-centric approach (based on the fivestage design thinking model); third, the produced documentation embraced the last three stages of the design thinking model concerned with the prototyping process; finally, digital fabrication tools were used to produce the prototype.

To evaluate the sustainability of each of the case studies based on the proposed conceptual framework, sustainability indicators were applied by considering criteria for evaluation that included product, process, and material (see Table 3). The criteria were taken or adapted from the referred literature. The motivation for analyzing these cases is to test key elements of the proposed framework and discuss their application in digital fabrication-based projects in an educational design context.

\subsection{Assessment}

Sustainability indicators were evaluated independently by two design experts using a five-point Likert scale, ranging from 1 (low) to 5 (high). Each expert had at least 10 years of experience in supporting students in prototyping using digital fabrication tools.

\section{Results}

Table 4 depicts the assessment (mean score) by the two design experts of the sustainability indicators for each of the three case studies. The level of agreement between the evaluators was tested with Cohen's [61] kappa coefficient. The value of kappa calculated in this study was 0.73 (Table 5). These $k$ values ranging from 0.61 to 0.81 represent significant agreement, and values ranging from 0.81 to 1.0 represent perfect agreement [62]. There is significant agreement among the assessors in most of the indicators, separate case studies, and overall.

\subsection{Case Study 1}

The first example is a design project entitled the escaping clock. The main goal was to produce a prototype of an alarm clock that can force people to wake up from bed to turn the clock off. The device contained motors, an LCD, and a microcontroller board as electric circuits to control all inputs and output devices. A tilt sensor was used to monitor whether clock was stable in its defined position, and a battery was used to power all electric devices. The complete documentation of the prototyping process was reported using a web-based blog. The prototype is shown in Figure 4a. 
Table 3. Evaluation criteria of sustainability indicators.

\begin{tabular}{|c|c|c|c|}
\hline Category & Indicator & Criteria & Reference \\
\hline \multirow{8}{*}{ Product } & Need & Does the user or community need it? & \multirow{8}{*}[22,63,64]{} \\
\hline & Suitable & Is it socially, culturally and environmentally appropriate? & \\
\hline & Access & Is it accessible and affordable now and in the future? & \\
\hline & Usability & Is it solution easily understood and easy to use? & \\
\hline & Quality & Is it robust and long-lasting? Does it meet the necessary standard? & \\
\hline & Adjustability & Is it flexible and adaptive to changing circumstances? & \\
\hline & Inclusive & $\begin{array}{c}\text { Is it inclusive of marginalized groups, or does it prioritize specific } \\
\text { user groups? }\end{array}$ & \\
\hline & Complementary & Does it support existing solutions and avoid unnecessary redundancy? & \\
\hline \multirow{8}{*}{ Process } & $\begin{array}{c}\text { Local } \\
\text { manufacture }\end{array}$ & Can it be manufactured locally? & \multirow{5}{*}[22,56,65]{} \\
\hline & Local control and repair & Can it be controlled, maintained, and repaired? & \\
\hline & Collaborative & Does it consider and engage with all stakeholders? & \\
\hline & Transparent & Is there supporting documentation? Is information shared? & \\
\hline & Scalable & Is the production process replicable and scalable? & \\
\hline & $\begin{array}{c}\text { Energy } \\
\text { consumption }\end{array}$ & $\begin{array}{c}\text { Is the shared use of machines considered? Are standby modes avoided? } \\
\text { Is the prototype made with the minimum possible iterations? }\end{array}$ & {$[25,45,48]$} \\
\hline & $\begin{array}{l}\text { Waste } \\
\text { reduction }\end{array}$ & $\begin{array}{l}\text { Is the design optimized using relevant software prior to manufacture? } \\
\text { Is an appropriate machine selected for the task? } \\
\text { Is the minimum number of iterations considered in making a prototype? }\end{array}$ & {$[23,45,46,54]$} \\
\hline & Emission & $\begin{array}{l}\text { Does the manufacturing process cause the emission of unwanted gas } \\
\text { (e.g., use of a laser cutter)? }\end{array}$ & {$[23,51,55]$} \\
\hline \multirow{4}{*}{ Material } & Recycle & $\begin{array}{c}\text { Is the use of environmentally friendly materials (like cardboard and } \\
\text { biomaterials) considered in making a prototype? }\end{array}$ & {$[23,39]$} \\
\hline & Reusability & $\begin{array}{c}\text { Are any used materials or electronic components utilized in making } \\
\text { the prototype? }\end{array}$ & {$[26,46]$} \\
\hline & Transportation & Is the prototype made using locally available material? & {$[25,27]$} \\
\hline & End of life & What are the useful parts after testing the prototype? & {$[23,56]$} \\
\hline
\end{tabular}

Based on the conceptual framework proposed in Section 3.3, sustainability indicators defined in Table 3 were used to evaluate the sustainability of the escaping clock project. The need indicator, related to the necessity to wake up to turn off the alarm, was satisfactory. The product was also evaluated as suitable, considering that it was culturally and environmentally appropriate. It was considered accessible and affordable for the users, bearing in mind that its component parts can be purchased at low cost, or made in any FabLab, and are simple to use. However, the fact that cardboard is not a durable material for long-term use compromises the quality of the prototype. Regarding adjustability, the product was considered of satisfactory value as it can be upgraded through additional features, such as communication with mobile phones. Since the prototype was designed using standard components made in the university FabLab, it was also regarded as successful in terms of the complementary technology and local manufacturing indicator. The prototype can be repaired locally in FabLab. While all stakeholders (users and makers) were involved in the design and prototyping process, the project was evaluated as the outcome of a collaborative effort. The prototyping process was deemed transparent, since the documentation was available on a web-based blog and accessible for instructors and the other teams participating in the course. While manufacturing the clock from scratch, no heavy machinery (e.g., laser cutter, $\mathrm{CNC}$, or 3D printer) requiring high energy consumption was required. Hence, a low amount of energy was consumed. Since a laser cutter machine was not required, 
the emission factor did not pose any threats. Cardboard was used to make the project casing and was assessed as a recyclable material. Only one design iteration was necessary to produce the prototype, and therefore no material was wasted. After testing the prototype, electronic components such as buttons, the LCD, and the microcontroller can be reused in other projects. A large part of the material used in the project was locally purchased, and hence no long-distance transportation was necessary. After the testing and dissembling phase, the material used in the prototype can be recycled and its electronic components reused, positively affecting the end-of-life indicator.

Table 4. Sustainability evaluation results for case studies 1 , 2, and 3.

\begin{tabular}{|c|c|c|c|c|c|}
\hline Category & Sustainability Indicators & Case Study 1 & Case Study 2 & Case Study 3 & Type of Indicators \\
\hline \multirow{8}{*}{ Product } & Need & 4 & 5 & 1 & \multirow{13}{*}{ 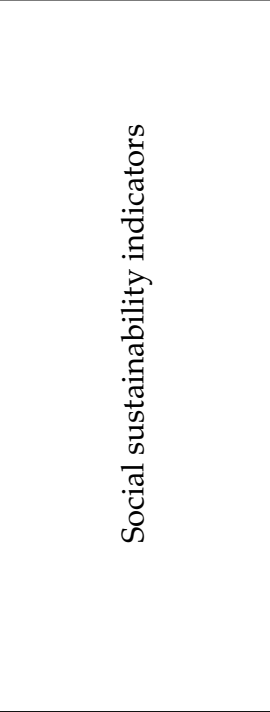 } \\
\hline & Suitable & 4.5 & 5 & 3 & \\
\hline & Access & 5 & 5 & 3.5 & \\
\hline & Usability & 5 & 4.5 & 1 & \\
\hline & Quality & 2 & 4 & 2 & \\
\hline & Adjustability & 4 & 3.5 & 1 & \\
\hline & Inclusive & 5 & 5 & 1 & \\
\hline & Complementary & 4.5 & 5 & 3 & \\
\hline \multirow{8}{*}{ Process } & Local Manufacture & 5 & 5 & 4 & \\
\hline & Local control and repair & 5 & 5 & 4 & \\
\hline & Collaborative & 5 & 5 & 5 & \\
\hline & Transparent & 5 & 5 & 5 & \\
\hline & Scalable & 1 & 4.5 & 1.5 & \\
\hline & Energy Consumption & 5 & 2 & 1.5 & \multirow{7}{*}{ 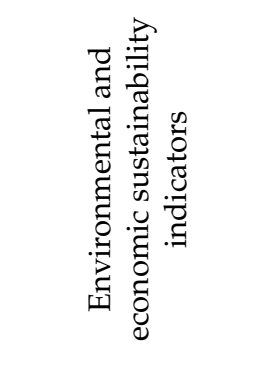 } \\
\hline & Waste reduction & 4.5 & 1 & 1.5 & \\
\hline & Emission & 5 & 1.5 & 1 & \\
\hline \multirow{4}{*}{ Material } & Recycle & 5 & 4 & 3 & \\
\hline & Reusability & 5 & 2 & 4 & \\
\hline & Transportation & 4 & 2 & 2 & \\
\hline & End of Life & 4 & 3 & 1.5 & \\
\hline
\end{tabular}

Table 5. Cohen's kappa k evaluation of agreement between the two referees.

\begin{tabular}{ccccc}
\hline Category or Case & Name & Kappa (к) & N of Valid Cases & Sig. \\
\hline \multirow{3}{*}{ Indicator } & Process & 0.607 & 24 & $<0.001$ \\
\cline { 2 - 5 } & Product & 0.721 & 24 & $<0.001$ \\
\cline { 2 - 5 } & Material & 0.889 & 12 & $<0.001$ \\
\hline \multirow{3}{*}{ Case study } & Case study 1 & 0.722 & 20 & $<0.001$ \\
\cline { 2 - 5 } & Case study 2 & 0.706 & 20 & $<0.001$ \\
\cline { 2 - 5 } & Case study 3 & 0.676 & 20 & $<0.001$ \\
\hline Overall & & 0.730 & 60 & $<0.001$ \\
\hline
\end{tabular}




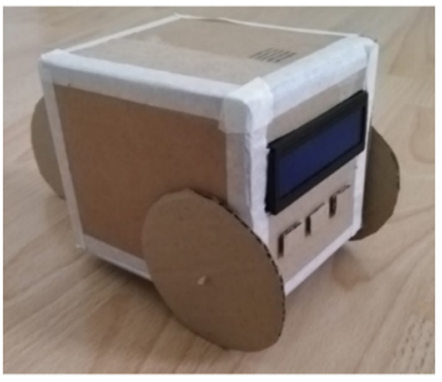

(a)

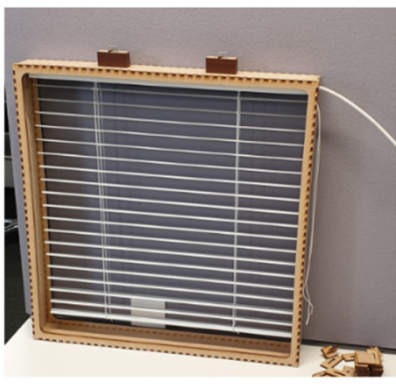

(b)

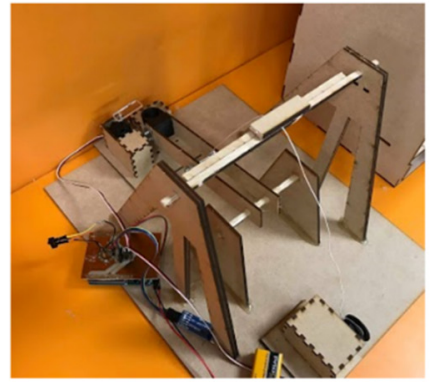

(c)

Figure 4. Design prototypes produced by the teams of students. (a) Case study 1: escaping clock; (b) case study 2: smart blinds; and (c) case study 3: catapult.

\subsection{Case Study 2}

This project is called smart blinds. The design team intended to tilt Venetian blinds at different angles automatically using light sensors. After making five iterations for the casing, they ended up with a medium-density fiberboard (MDF) casing to hold the blinds and electronic parts of the project. The casing was made using a laser cutter and designed through an online tool called "Boxes.py". Electronic components included a photoresistor as a light detecting sensor, servo motors as actuators to tilt blinds, and a microcontroller board to control all parts of the project. Two attempts were made to make a printed circuit board (PCB) through a CNC milling machine. This PCB was used to integrate all the components on a single board. All electronic parts were imported, and MDF for the casing was locally available (see Figure 4b).

Manually adjusting window blinds daily can be an annoying experience for users. Therefore, products such as smart blinds are very much needed. This product causes no environmental damage and is socially suitable. High-quality materials and processes like MDF for the casing, PCB for electronic components, and automatic control using sensors turn the smart blinds into a good quality prototype with high fidelity (quality, access, and usability). A feature that makes this prototype inclusive is that it can be automatically operated, and hence users should not concern themselves with controlling the functions. Moreover, the product can communicate with other devices and can be adjusted according to user requirements. Another important factor is that it is complementary with existing technology, machines, and other commercially available electronic components. The product is locally and collaboratively manufactured in a local FabLab, and the documentation is available on a website blog. This reflects the transparency of the process, which can be an advantage when repair might be needed. The production process is also scalable, as the casing is cut through a laser cutter. Consequently, the same files can be used for large-scale production. The MDF material used for casing is environmentally friendly and therefore can be recycled. On the other hand, the electronic components are new and in the future can be reused in any other prototypes. In contrast, sustainability indicators that were not achieved in this design project are energy consumption, waste reduction, emission, and transportation, since most of the product components were imported from foreign countries. Moreover, multiple attempts were made to optimize the casing using a laser cutter, which caused an increase in waste generated, higher energy consumption, and unwanted gas emitted. After testing the prototype, MDF could be recycled and some electronic components could be reused; hence, the end-of-life indicator was partially achieved (see Table 4).

\subsection{Case Study 3}

This project is named Catapult. The objective was to design a small catapult with actuators, which can be seen as elements changing electrical energy to mechanical that operate and control the device via a mobile application. The project was completed after producing three prototypes using cardboard material and a laser cutter. The final prototype 
included two 3D printed components. The electronics parts were motors, Bluetooth connection modules, and a dedicated electronic circuit to control all the electronic devices of the project. A mobile application was created to communicate with the product (see Figure 4c).

This project incorporates the element of fun and means to learn fabrication skills and therefore was not intended to fulfill any kind of user needs. The prototype was evaluated as culturally and environmentally appropriate (suitable). It uses cheap and commercially available components (access). The Catapult is a purpose-built prototype, and hence usability was not a problem. However, its adjustability for including further features was possible. It was evaluated as a low-quality prototype, since it uses cardboard as the main structure material and provides no protection to electronic circuits. The project was made in collaboration with a team of students working in a local FabLab (local manufacture) for learning purposes, and it does not target other users. Therefore, it does not fulfill the criterion of inclusiveness. Transparency was achieved given that the complete documentation for the process was available on a web blog. Since the electronic components were imported, some parts of the project needed long-distance transportation. Since three prototype iterations took place during the prototyping process, waste reduction was disregarded, and vast energy was consumed. Moreover, the prototyping process generated unwanted gas emissions as a laser cutter was used multiple times. While the project used purpose-built electronic circuits, only a few components (Bluetooth and motors) could be reused after the testing phase. Therefore, the end-of-life indicator was not satisfactory (see Table 4).

\section{Discussion}

Findings and observations derived from the assessment of the case studies are discussed concerning the proposed framework. The section is organized into three parts dealing with product, process, and material.

\subsection{Product}

The sustainability indicator under the product category reflected the level of social sustainability of the design prototype [22,29]. From the analysis of the case studies, the overall importance of the social sustainability indicators was observed to be directly related to the quality of a design project. This was particularly evidenced in case studies 1 and 2, where most social sustainability indicators were attained. Both designs were found to be socially viable, since they were used to solve real-life problems. Therefore, it can be said that the social sustainability indicator is largely concerned with the design and usability of the product. In educational settings, a larger awareness of social sustainability indicators can make students' projects more practical and beneficial for society.

\subsection{Process}

In the proposed framework, the sustainability of the prototyping process is divided into two parts: social sustainability and economic and environmental sustainability. The social sustainability of the fabrication process hinges on five factors: local manufacture, local repair and control, collaborative, transparent, and scalable [22]. In all case studies, four out of the five indicators were met. This is because in educational prototyping activities, students can design the full prototype locally in FabLab. This makes the design activity collaborative and locally manufactured. Students also shared the documentation generated during prototyping with their instructors, which made the process more transparent. Hence, it can be said that teamwork in FabLab environments contributes to sharing and communicating information, which makes the prototyping process sustainable.

The three indicators, energy consumption, waste reduction, and emission, were identified in this study as responsible for environmental and economic sustainability indicators of the prototyping process. A reason all three indicators were attained in case study 1 is that the prototype was produced in only one iteration without using machines like a laser cutter, which led to minimum waste. In contrast, in case studies 2 and 3, prototypes were 
produced after three to five iterations, which involved a heavier use of the laser cutter machine and correspondingly higher energy consumption and induced waste. Hence, reducing the number of iterations in the prototyping activity can contribute to reducing energy usage, waste, and gas emissions. However, this contradicts the philosophy of FabLabs, which stated that multiple iterations of prototypes are considered helpful in improving design learning [66]. As a tradeoff and as a way to reduce iterations, it is recommended to optimize the design activity using CAD software before producing the concrete prototype.

\subsection{Material}

The type of material used during the prototyping activity can also be helpful to improve design sustainability when the material is recyclable [23]. This was the case in all three examples analyzed in this study. To improve suitability, microcontrollers, integrated circuits, sensors, and motors employed in the prototyping activity can be reused in the same design or in future projects [46]. It was observed that in case studies 1 and 2, the reusability of electronic components was present. This is because general-purpose electronic components were used. Employing general purpose electronic boards and sensors in prototypes allows reusability in future prototypes. Finally, local availability of materials and parts was found to reduce transportation costs, hence improving design sustainability [26,46]. This finding is aligned with Fleischmann et al. [38], who used cork-a naturally available and renewable material-in a project located in Portugal and found that this had a significantly positive impact on the sustainability of the final design. The process through which cork is made also causes zero emissions of harmful gases into the environment [67].

\subsection{Guidelines for Sustainable Designing and Prototyping}

Based on the study findings, guidelines can be suggested to ensure sustainable prototyping of design artifacts. (1) Follow the systematic approach provided by the design thinking model. (2) Involve users in the designing process and incorporate their needs and desires at the early stages. (3) Design a product/prototype making use of the locally available materials, since this will help to fabricate environmentally friendly and economic end products. (4) Use CAD software to optimize the design in terms of material usage and time required for machining. (5) Avoid idle modes of machines and maximize machine utilization by engaging in more than one job at a time to make this process more efficient.

(6) Select appropriate machines by considering their energy usage and material wastage. (7) Do your best to reuse electronic components from prior prototypes. (8) Think about the environmental impact of the materials before selecting them for the prototype. (9) Make use of a general-purpose electronic circuit to increase reusability. (10) Disassemble the prototype after testing and recycle used material to the best of your abilities.

\section{Conclusions}

Prototyping is an important aspect of design education, new product development, learning digital fabrication skills, and STEM education. This activity is carried out in FabLabs and makerspaces around the globe. The topic of sustainability is a main concern for digital fabrication tools used for product design, and its many facets have been widely studied over the last decade. This study proposes a comprehensive and novel conceptual framework that incorporates the Stanford five-stage design thinking model, key sustainability indicators identified in the literature (i.e., social, environmental, and economic), and digital fabrication components (i.e., material and process) aimed at evaluating sustainable prototyping processes and outcomes. The framework was tested against three case studies that served as concrete examples to discuss best practices in the educational environment.

From the literature review conducted in this study, it is also concluded that sustainability concerning prototyping in design education is a relatively unexplored field that deserves more investigation. Hence, the conceptual framework can be of assistance for researchers as well as for educational programs interested in promoting and evaluating 
sustainability issues in environments such as FabLabs. This work is limited to prototyping using digital fabrication tools. Therefore, it can be extended to and compared with other types of prototyping processes and tools. The environmental and economic sustainability indicators identified in this study can also be employed in sustainability evaluation for industrial and commercial product designs using new product development strategies. Moreover, no sustainability article specifically focusing on purely economic factors in relation to digital fabrication was found in the literature review; hence, no sustainability indicator that specifically focuses on economic aspects alone was included in the proposed conceptual framework. However, the proposed framework potentially could be extended in the future to include such an indicator.

Author Contributions: Conceptualization, H.C., G.V.G., S.A.S.; methodology, S.A.S., H.C., G.V.G.; validation, S.A.S., G.V.G.; investigation, S.A.S., G.V.G.; data curation, S.A.S., G.V.G.; writing—original draft preparation, S.A.S.; writing-review and editing, H.C., S.A.S., G.V.G.; visualization, S.A.S.; supervision, H.C., G.V.G.; funding acquisition, G.V.G. All authors have read and agreed to the published version of the manuscript.

Funding: This research was funded by Academy of Finland 6Genesis Flagship grant number 318927.

Institutional Review Board Statement: Not Applicable.

Informed Consent Statement: Not applicable.

Data Availability Statement: The data presented in this study are available on request from the corresponding author.

Acknowledgments: This study has been financially supported by Academy of Finland 6Genesis Flagship (grant 318927).

Conflicts of Interest: The authors declare no conflict of interest.

\section{References}

1. Yang, M.C. A Study of Prototypes, Design Activity, and Design Outcome. Des. Stud. 2005, 26, 649-669. [CrossRef]

2. Van Harmelen, M. Exploratory User Interface Design Using Scenarios and Prototypes. In Proceedings of the Conference of the British Computer Society, Human-Computer Interaction Specialist Group on People and Computers V; Cambridge University Press: Cambridge, MA, USA, 1 February 1990; pp. 191-201.

3. Kirjavainen, A.; Nousiainen, T.; Kankaanranta, M. Prototyping in Educational Game Design; CiteSeerX: Montréal, QC, Canada, 24 April 2005; p. 3.

4. Beaudouin-Lafon, M.; Mackay, W. Prototyping tools and techniques. In The Human-Computer Interaction Handbook: Fundamentals, Evolving Technologies and Emerging Applications; L. Erlbaum Associates Inc.: Mahwah, NJ, USA, 2002; pp. 1006-1031. ISBN 978-0-8058-3838-1.

5. Lande, M.; Leifer, L. Prototyping to Learn: Characterizing Engineering Students' Prototyping Activities and Prototypes. In Proceedings of the DS 58-1: Proceedings of ICED 09, Palo Alto, CA, USA, 27 August 2009; Volume 1, pp. 507-516.

6. Lim, Y.-K.; Stolterman, E.; Tenenberg, J. The Anatomy of Prototypes: Prototypes as Filters, Prototypes as Manifestations of Design Ideas. ACM Trans. Comput.-Hum. Interact. 2008, 15, 7:1-7:27. [CrossRef]

7. Paio, A.; Eloy, S.; Rato, V.M.; Resende, R.; de Oliveira, M.J. Prototyping Vitruvius, New Challenges: Digital Education, Research and Practice. Nexus Netw. J. 2012, 14, 409-429. [CrossRef]

8. Jensen, L.S.; Özkil, A.G.; Mortensen, N.H. Prototypes In Engineering Design: Definations and Strategies. In Proceedings of the DESIGN 2016, Dubrovnik, Croatia, 16 May 2016; pp. 821-830.

9. How To Make A Product Prototype In The Digital Fabrication Age. Available online: https://www.ponoko.com/blog/how-tomake/how-to-make-a-product-prototype/ (accessed on 17 December 2020).

10. Tschimmel, K. Design Thinking as an Effective Toolkit for Innovation. In Proceedings of the ISPIM Conference Proceedings; The International Society for Professional Innovation Management (ISPIM): Manchester, UK, 2012; pp. 1-20.

11. Valamanesh, R.; Shin, D. Tangible Ideation: How Digital Fabrication Acts as a Catalyst in the Early Steps of Product Development. In Proceedings of the DS 76: E\&PDE 2013, Dublin, Ireland, 6 September 2013; pp. 635-640.

12. Buswell, R.A.; da Silva, W.R.L.; Bos, F.P.; Schipper, H.R.; Lowke, D.; Hack, N.; Kloft, H.; Mechtcherine, V.; Wangler, T.; Roussel, N. A Process Classification Framework for Defining and Describing Digital Fabrication with Concrete. Cement Concrete Res. 2020, 134, 106068. [CrossRef]

13. Popescu, M.; Rippmann, M.; Liew, A.; Reiter, L.; Flatt, R.J.; Van Mele, T.; Block, P. Structural Design, Digital Fabrication and Construction of the Cable-Net and Knitted Formwork of the KnitCandela Concrete Shell. Structures 2020, S2352012420300655. [CrossRef] 
14. Kim, D.Y. A Design Methodology Using Prototyping Based on the Digital-Physical Models in the Architectural Design Process. Sustainability 2019, 11, 4416.

15. Milara, I.S.; Georgiev, G.V.; Riekki, J.; Ylioja, J.; Pyykkonen, M. Human and Technological Dimensions of Making in FabLab. Des. J. 2017, 20, S1080-S1092. [CrossRef]

16. Soomro, S.A.; Georgiev, G.V. A Framework to Analyse Digital Fabrication Projects: The Role of Design Creativity. In Proceedings of the Design Society (ICDC 2020), Oulu, Finland, 26-28 August 2020; pp. 367-374. [CrossRef]

17. Iwata, M.; Pitkänen, K.; Laru, J.; Mäkitalo, K. Exploring Potentials and Challenges to Develop Twenty-First Century Skills and Computational Thinking in K-12 Maker Education. Front. Educ. 2020, 5. [CrossRef]

18. Milara, I.S.; Pitkänen, K.; Laru, J.; Iwata, M.; Orduña, M.C.; Riekki, J. STEAM in Oulu: Scaffolding the Development of a Community of Practice for Local Educators around STEAM and Digital Fabrication. Int. J. Child-Comput. Interact. 2020, $26,100197$. [CrossRef]

19. Gershenfeld, N. How to Make Almost Anything. 2012. Available online: https://www.foreignaffairs.com/articles/2012-09-27 /how-make-almost-anything (accessed on 23 January 2021).

20. Blikstein, P. Maker Movement in Education: History and Prospects. In Handbook of Technology Education; de Vries, M.J., Ed.; Springer International Handbooks of Education; Springer International Publishing: Cham, Switzerland, 2018; pp. 419-437. ISBN 978-3-319-44686-8.

21. Hamblen, J.O.; van Bekkum, G.M.E. An Embedded Systems Laboratory to Support Rapid Prototyping of Robotics and the Internet of Things. IEEE Trans. Educ. 2013, 56, 121-128. [CrossRef]

22. Corsini, L.; Moultrie, J. Design for Social Sustainability: Using Digital Fabrication in the Humanitarian and Development Sector. Sustainability 2019, 11, 3562.

23. Lazaro Vasquez, E.S.; Wang, H.-C.; Vega, K. Introducing the Sustainable Prototyping Life Cycle for Digital Fabrication to Designers. In Proceedings of the 2020 ACM Designing Interactive Systems Conference, Eindhoven, The Netherlands, 6-10 July 2020; pp. 1301-1312.

24. Kohtala, C.; Hyysalo, S. Anticipated Environmental Sustainability of Personal Fabrication. J. Clean. Prod. 2015, 99, 333-344. [CrossRef]

25. Agusti-Juan, I.; Hubert, G. Environmental Design Guidelines for Digital Fabrication. J. Clean Prod. 2017, 142, 2780-2791. [CrossRef]

26. Kim, S.; Paulos, E. Practices in the Creative Reuse of E-Waste. In Proceedings of the SIGCHI Conference on Human Factors in Computing Systems; Association for Computing Machinery: New York, NY, USA, 7 May 2011; pp. 2395-2404.

27. Prendeville, S.; Hartung, G.; Purvis, E.; Brass, C.; Hall, A. Makespaces: From Redistributed Manufacturing to a Circular Economy. In Sustainable Design and Manufacturing 2016; Setchi, R., Howlett, R.J., Liu, Y., Theobald, P., Eds.; Smart Innovation, Systems and Technologies; Springer International Publishing: Cham, Switzerland, 2016; Volume 52, pp. 577-588. ISBN 978-3-319-32096-0.

28. Millard, J.; Sorivelle, M.N.; Deljanin, S.; Unterfrauner, E.; Voigt, C. Is the Maker Movement Contributing to Sustainability? Sustainability 2018, 10, 2212. [CrossRef]

29. Smith, R.C.; Iversen, O.S. Participatory Design for Sustainable Social Change. Des. Stud. 2018, 59, 9-36. [CrossRef]

30. Kohtala, C. Making "Making" Critical: How Sustainability Is Constituted in Fab Lab Ideology. Des. J. 2017, 20, 375-394. [CrossRef]

31. Nascimento, S.; Pólvora, A.; Paio, A.; Oliveira, S.; Rato, V.; Oliveira, M.J.; Varela, B.; Sousa, J.P. Sustainable Technologies and Transdisciplinary Futures: From Collaborative Design to Digital Fabrication. Sci. Cult. 2016, 25, 520-537. [CrossRef]

32. Braga, M.; Guttmann, G. The Knowledge Networks in a Makerspace: The Topologies of Collaboration. Int. J. Sci. Math. Educ. 2019, 17, S13-S30. [CrossRef]

33. Unterfrauner, E.; Hofer, M.; Pelka, B.; Zirngiebl, M. A New Player for Tackling Inequalities? Framing the Social Value and Impact of the Maker Movement. Soc. Incl. 2020, 8, 190-200. [CrossRef]

34. Anastasiadou, C.; Vettese, S. "From Souvenirs to 3D Printed Souvenirs". Exploring the Capabilities of Additive Manufacturing Technologies in (Re)-Framing Tourist Souvenirs. Tour. Manag. 2019, 71, 428-442. [CrossRef]

35. Maravilhas, S.; Martins, J. Strategic Knowledge Management a Digital Environment: Tacit and Explicit Knowledge in Fab Labs. J. Bus. Res. 2019, 94, 353-359. [CrossRef]

36. Unterfrauner, E.; Shao, J.; Hofer, M.; Fabian, C.M. The Environmental Value and Impact of the Maker Movement-Insights from a Cross-Case Analysis of European Maker Initiatives. Bus. Strateg. Environ. 2019, 28, 1518-1533. [CrossRef]

37. Cappa, F.; Del Sette, F.; Hayes, D.; Rosso, F. How to Deliver Open Sustainable Innovation: An Integrated Approach for a Sustainable Marketable Product. Sustainability 2016, 8, 1341. [CrossRef]

38. Fleischmann, K.; Hielscher, S.; Merritt, T. Making Things in Fab Labs: A Case Study on Sustainability and Co-Creation. Dig. Creat. 2016, 27, 113-131. [CrossRef]

39. Maldini, I. Attachment, Durability and the Environmental Impact of Digital DIY. Des. J. 2016, 19, 141-157. [CrossRef]

40. Nascimento, S.; Pólvora, A. Social Sciences in the Transdisciplinary Making of Sustainable Artifacts. Soc. Sci. Inf. 2016, 55, 28-42. [CrossRef]

41. Katterfeldt, E.-S.; Dittert, N.; Schelhowe, H. Designing Digital Fabrication Learning Environments for Bildung: IMPLICATIONS from Ten Years of Physical Computing Workshops. Int. J. Child-Comput. Interact. 2015, 5, 3-10. [CrossRef]

42. Missimer, M.; Robèrt, K.-H.; Broman, G. A Strategic Approach to Social Sustainability—Part 2: A Principle-Based Definition. J. Clean. Prod. 2017, 140, 42-52. [CrossRef]

43. Khan, R. How Frugal Innovation Promotes Social Sustainability. Sustainability 2016, 8, 1034. [CrossRef] 
44. Benoît, C.; Norris, G.A.; Valdivia, S.; Ciroth, A.; Moberg, A.; Bos, U.; Prakash, S.; Ugaya, C.; Beck, T. The Guidelines for Social Life Cycle Assessment of Products: Just in Time! Int. J. Life Cycle Assess. 2010, 2, 156-163. [CrossRef]

45. Faludi, J.; Bayley, C.; Bhogal, S.; Iribarne, M. Comparing Environmental Impacts of Additive Manufacturing vs Traditional Machining via Life-Cycle Assessment. Rapid Prototyp. J. 2015, 21, 14-33. [CrossRef]

46. Vyas, D.; Vines, J. Making at the Margins: Making in an Under-Resourced e-Waste Recycling Center. Proc. ACM Hum.-Comput. Interact. 2019, 3, 188:1-188:23. [CrossRef]

47. Birtchnell, T.; Urry, J. Fabricating Futures and the Movement of Objects. Mobilities 2013, 8, 388-405. [CrossRef]

48. Faludi, J.; Ganeriwala, R.; Kelly, B.; Rygg, T.; Yang, C. Sustainability of 3D Printing vs. Machining: Do Machine Type \& Size Matter? In Proceedings of the EcoBalance 2014, Tsukuba, Tokyo, 27-30 October 2014.

49. Kreiger, M.; Pearce, J.M. Environmental Life Cycle Analysis of Distributed Three-Dimensional Printing and Conventional Manufacturing of Polymer Products. ACS Sustain. Chem. Eng. 2013, 1, 1511-1519. [CrossRef]

50. Luo, Y.; Ji, Z.; Leu, M.-C.; Caudill, R.J. Environmental Performance Analysis of Solid Freedom Fabrication Processes. In Proceedings of the IEEE International Symposium on Electronics and the Environment, Danvers, MA, USA, 13 May $1999 ;$ p. 7.

51. How Much Combustible Gas Is Released From Laser Engraving. Available online: http://support.epiloglaser.com/article/8205 /75905/ (accessed on 14 December 2020).

52. How Sustainable Is Digital Fabrication? Available online: https:/ /www.lowtechmagazine.com/2014/03/how-sustainable-isdigital-fabrication.html (accessed on 15 December 2020).

53. Gonzalez, A. Machine Tool Utilisation Phase: Costs and Environmental Impacts with a Life Cycle View; KTH Royal Institute of Technology: Stockholm, Sweden, 2007.

54. Peeters, B.; Kiratli, N.; Semeijn, J. A Barrier Analysis for Distributed Recycling of 3D Printing Waste: Taking the Maker Movement Perspective. J. Clean. Prod. 2019, 241, 118313. [CrossRef]

55. O'Neill, K. Laser-Generated Airborne Contaminants from a Desktop Laser Cutter and Engraver; The University of Oklahoma Health Sciences Center: Oklahoma City, Oklahoma, 2017.

56. Maxwell, D.; van der Vorst, R. Developing Sustainable Products and Services. J. Clean. Prod. 2003, 11, 883-895. [CrossRef]

57. Angrisani, L.; Arpaia, P.; Bonavolontá, F.; Moccaldi, N.; Schiano Lo Moriello, R. A “Learning Small Enterprise” Networked with a FabLab: An Academic Course 4.0 in Instrumentation and Measurement. Meas. J. Int. Meas. Confed. 2020, 150. [CrossRef]

58. Barton, A.C.; Tan, E.; Greenberg, D. The Makerspace Movement: Sites of Possibilities for Equitable Opportunities to Engage Underrepresented Youth in STEM. Teach. Coll. Rec. 2017, 119, 060308.

59. Tu, J.-C.; Liu, L.-X.; Wu, K.-Y. Study on the Learning Effectiveness of Stanford Design Thinking in Integrated Design Education. Sustainability 2018, 10, 2649. [CrossRef]

60. Lenton, E.; Dineen, C. Set It and Forget It (Almost): How We Make DIY 3D Printing Work in Our Library. Public Serv. Q. 2016, 12, 179-186. [CrossRef]

61. Cohen, J. Statistical Power Analysis. Curr. Dir. Psychol. Sci. 1992, 1, 98-101. [CrossRef]

62. Altman, D.G. Practical Statistics for Medical Research; Chapman \& Hall/CRC Press: New York, NY, USA, 1999.

63. Kadir, S.A.; Jamaludin, M. Universal Design as a Significant Component for Sustainable Life and Social Development. Procedia Soc. Behav. Sci. 2013, 85, 179-190. [CrossRef]

64. Melles, G.; de Vere, I.; Misic, V. Socially Responsible Design: Thinking beyond the Triple Bottom Line to Socially Responsive and Sustainable Product Design. CoDesign 2011, 7, 143-154. [CrossRef]

65. Thomas, A. Design, Poverty, and Sustainable Development. Des. Issues 2006, 22, 54-65. [CrossRef]

66. Zarraonandia, T.; Dodero, J.M.; Fernández, C.; Paloma Díaz, I.A. Iterative Design of Learning Processes. In Computers and Education: E-Learning, From Theory to Practice; Fernández-Manjón, B., Sánchez-Pérez, J.M., Gómez-Pulido, J.A., Vega-Rodríguez, M.A., Bravo-Rodríguez, J., Eds.; Springer: Dordrecht, The Netherlands, 2007; pp. 163-177. ISBN 978-1-4020-4914-9.

67. Tártaro, A.S.; Mata, T.M.; Martins, A.A.; Esteves da Silva, J.C.G. Carbon Footprint of the Insulation Cork Board. J. Clean. Prod. 2017, 143, 925-932. [CrossRef] 